Tertiary education courses, especially those in the arts and social sciences, generally require students to write compositions based on prescribed readings. Although students with poor skills in "appropriating" arguments contained in such readings are at a disadvantage, and may even be accused of plagiarism, this aspect of writing has been relatively neglected in published teaching materials for English for Academic Purposes. This article describes various techniques for promoting academic competence by helping students to summarize, synthesize and evaluate prescribed readings legitimately.

Despite the continuing growth in the number of coursebooks on English for Academic Purposes (EAP), it is often difficult for teachers to match published materials with the highly specific needs of their own students. One partial solution is a set of strategies and procedures which can be used with texts relevant to the students' own disciplines. This article suggests several strategies which I have found useful. These strategies were developed in an EAP reading and writing course that is part of a B.A. Program in English as a Foreign Language (EFL) for overseas undergraduate students at Stirling University. Since the EAP course should be seer. particularly in the context of the first semester's overall structure, I shall sketch the other two components of the first semester program.

On entering the B.A. in EFL, the students, who come from a variety of backgrounds (Greek, Cypriot, French, Chinese, and Japanese), take three courses: one in General English, which aims to improve overall control of the language; one in Contextual Studies, which aims to provide some of the social, historical and cultural background necessary to understand the content of further university courses; and finally EAP. The first semester of the EAP course has concentrated on reading and particularly writing, because these are the skills most urgently required in the university system. Stirling University has quite rigorous continuous assessment plus examinations in most university departments, and by far the majority of the departments assesses written work only. The students therefore need to write efficiently and well, drawing on a range of prescribed texts, if they are to succeed. 
This brings me to the problem. In the late 1980's, when we began developing the BA in EFL, available published EAP materials did not seem to satisfy the needs of our student intake. There were various reasons for this. Among them were the tendency of EAP materials to be slanted towards science or business rather than the humanities and social sciences that our students preferred. Those materials that were relevant to our students had a different kind of weakness: they tended to present information from a single point of view. Students were typically asked to summarize or present a single, fairly uncontentious, argument (e.g. on the dangers of environmental pollution). Again, this intellectual shallowness may be well-intentioned. As Campbell (1990) rightly states: "...writing is such a complex process that attention cannot easily be given to everything at the same time" (p. 221). If students have to read, organize, plan, compose and redraft, then perhaps we do not want to confuse them further with a variety of conflicting viewpoints.

On the other hand, perhaps we do. The typical undergraduate does not simply have to read, understand and summarize texts: students also have to use these texts in their own written work. Students often use their background reading badly, and of course the extreme example of this is (in our terms) plagiarism, often unintentional. Campbell's (1990) study of non-native and native speakers' referencing strategies when faced with an anthropology text suggests that plagiarism is more of a problem for non-native speakers than for native speakers:

The results of this study show that when these [overseas] university students integrated information from the anthropology text into their in-class compositions, they relied on copying as their primary method of text integration, and they referenced the anthropology author too little. These students have the ability to paraphrase, summarize, quote and integrate information from a source text into their original examples and explanations; however, they need to be given ample opportunity to practice this type of writing in order to edit out instances of copying.

(Campbell 1990, p. 225)

My own experience accords with Campbell's findings, which suggest that non-native speakers are dominated by the texts they must read and recycle. The question, then, is how to design activities which practise the skills of "appropriating" the arguments of others-legiti- 
mately. The Stirling EAP reading and writing course favoured a three-pronged approach:

1. Summary techniques: analysis of the language and especially the discourse structure of authentic academic texts (not only popularizations). Academic and professional journals are a good source of texts for this: familiar ESL journals such as the TESL Canada Journal or the TESOL Quarterly go down well!

2. Evaluation techniques: reading not only to understand but also to criticise, positively or negatively. This is the stage where perhaps the function of quotation is trickiest for students.

3. Mini-assignments: semi-controlled compositions based primarily on given background reading, which must be quoted from. These are home-based assignments (plus a similar end-of-semester exam), and they go through at least two drafts. These are the basis of the semester grade.

Let us now turn to representative activities for each approach.

\section{SUMMARY TECHNIQUES}

Campbell (1990, p. 213) cites a range of research which demonstrates that increased reading ability leads to improved summaries and syntheses. General reading skills are tackled as part of the General English course in the BA in EFL, which left me free to concentrate on more specific skills. Over the last three years I concentrated on raising the students' awareness of a general "logical sequence" which serves as a template for much academic (as well as everyday) English discourse: the problem-solution pattern. This pattern is not, of course, the only text structure available in academic English. Other useful structures include simple lists, question-answer sequences, and varieties of chronological ordering. But insofar as problem-solving is a valued technique in academic procedure (whereas listing may be stigmatised, except where specifically requested), the problem-solution pattern is a useful weapon in the students' arsenal.

The problem-solution pattern derives from the work of Winter (1982) on the semantic relationships between clauses, and how they are lexically signalled. His work has been developed by Hoey (1983) and Jordan (1984): they use the principles of clause relations to 
analyse longer stretches of discourse, though not usually longer than a few paragraphs. Of the three books, Jordan's is closest to a practical text-book or guide, and he concentrates on the problemsolution pattern in particular. His argument is that texts can frequently be broken down into stages corresponding to the labels:

SITUATION, including a

PROBLEM, that is, the aspect of a situation eliciting a

RESPONSE, which when put into effect gives a

RESULT, which in turn elicits from the writer an

EVALUATION, which may be positive or negative.

A negative evaluation is equivalent to a new problem, which will require a new response, and so the sequence continues.

A positive evaluation would normally mean the end of the sequence.

I am aware that some influential EAP theorists and practitioners have reservations about the Problem-Solution pattern. Swales (1990), for example, reiterates his feeling that the pattern is too general to account satisfactorily for some detailed textual patterns, such as those found in academic article introductions. However, it is the very generality of the pattern that makes it appealing to the EAP teacher who is trying to give substantial but not too specific advice to students writing a range of text-types (albeit a narrow range: essays, reports, exams, etc). Activities utilising the ProblemSolution pattern provide students with at least one useful and generalisable "attack skill" for reading many academic texts, as well as a useful model for summaries and essay plans.

But how is this theory transformed into classroom practice? There are a variety of ways, but one of the most useful is a simple adaptation of the familiar activity of jigsaw reading. Once students have been introduced to the logical sequence-via a brief model and some work on lexical signals (e.g. problem signals such as "issue/gap/controversy/deficiency") - the teacher can further familiarize students with the pattern and encourage summary skills by adapting a number of widely-used procedures:

1. Find a text which conforms to the Problem-Solution pattern. These may vary in length according to the familiarity of the class with the procedure. For example, I have used passages from advanced ESL textbooks, as well as authentic, short articles (up to three pages long) from academic and professional journals. 
2. Divide the text into stages corresponding as closely as possible to the main Problem-Solution pattern. Photocopy the initial stage, and one of the later stages, onto one sheet of paper one copy of which will be distributed to each student group). Photocopy and enlarge the remaining stages onto separate sheets of paper and post them on different parts of the classroom wall.

3. Divide the learners into groups of between two and five. One member of the group is the nominated Writer, and should remain seated. The others are Reporters, and may move around.

4. The Writer initially summarises the opening and later stages of the text, and predicts the intervening content. The Reporters go back and forth from the Writer to the wall posters, orally reporting the main points contained there. Together, the group reconstructs a summary of the text.

5. If possible, this summary should be transferred to an OHP transparency and different groups' versions compared in a concluding class session (perhaps alongside a suggested model, written by the teacher). Differences and similarities can be discussed.

Such an activity, or a variation on it, encourages (a) the abstraction of the main points of a reading text; (b) the recognition of any signals of discourse stage present in a text; and (c) awareness of overall text structure. The information gap format incidentally encourages collaborative learning, and also oral skills.

\section{EVALUATION TECHNIQUES}

Efficient summarising and paraphrasing of the content of reading texts is therefore one "appropriation" skill. The second is critical reading, or evaluation. There is a slight danger of ambiguity here, since, as we have seen, texts conforming to the Problem-Solution pattern generally contain an evaluation, which the students may report. But they also have to evaluate this evaluation, by endorsing it, qualifying it or rejecting it and offering an alternative. I find that the overwhelming majority of students unquestioningly endorse the findings of the background reading, even when there is available extra-textual evidence to the contrary. I have sometimes used an old EFL training guide, written and published in Russia, which confidently claims that all British university staff speak with standard "BBC" accents. I am constantly amazed at how many students studying in Stirling and daily encountering Scottish lecturers with strong Scottish accents continue to endorse this guide's 
rather naive claim. The exercise below is designed to elicit a negative evaluation. It usually does, for a variety of reasons which form the BASIS for the ASSESSMENT of the (here hypothetical) response and results to a vexed problem:

Read the following summary of an argument put forward by an ex-Principal of a Scottish University. Give a POSITIVE or a NEGATIVE evaluation, giving an ASSESSMENT and a BASIS.
SITUATION + The population of the world is growing fast. PROBLEM Overpopulation will soon result in shortages of resources, famine and probably war.

RESPONSE A chemical contraceptive should be put into the food of every adult, so that only people who fast for a period of time (eg a week) will be able to have children.

RESULTS As a result, the population expansion should quickly be halted, and global catastrophe should be avoided.

ASSESSMENT

BASIS

Because students do tend to agree with other people's arguments, quotation skills come into play. Campbell (1990) does not investigate the functions of the quotations she analyses-her main concern is how close in wording they are to the originals-but she does observe that there is a high proportion of quotations in the final paragraphs compared to the opening paragraphs and body of the compositions (p. 219). This observation again accords with a tendency which I find in several students' essays: arguments are developed out of personal knowledge and experience, and quotations from background reading are brought in (if at all) at the conclusion as clinching authoritative support, or as pithy topic closers. 
What is wrong with this? Without wishing at all to devalue personal experience and observation, I would argue that there are certain requirements of undergraduate essays: (a) familiarity with at least some of the background reading that deals with the consensus of received opinion about a subject, and (b) a demonstrable ability to judge the foundations of the evidence, on which rest the knowledge claims expressed by the background reading. The first requirement-familiarity-may be met using the quotation as an authority. The second requirement-the demonstrable ability to evaluate knowledge claims - is not.

It is revealing to ask students why they have used a particular quotation. It is surprising how many answer that it is to prove that they have read the background text, or even just to fill up space. In class I draw attention to three main functions of quotation:

1. As an authority. Students are advised to use authoritative quotations to establish assumptions which will be used as part of an argument (i.e. mainly at the RESPONSE stage). They should be wary of using authoritative quotations to clinch an argument (i.e. by simply reporting another's EVALUATION in the final stage.)

2. As a "straw man". Perhaps a more useful technique in the classroom, as I have suggested above, is to encourage students to seek out arguments with which they disagree. This is of course not without dangers, as some students become hypercritical, but it is often easier for students to produce evidence for negative rather than positive evaluations.

3. For comparison. Parallel or related studies may be cited to give a measure of indirect support for an argument or procedure. For example, the results of disciplinary reforms in UK schools may be used in support of or against an argument for similar reforms in the student's native country. Here differences as well as similarities between the two contexts should not be forgotten in the student's own evaluation.

The common factor in these three functions of quotation, and a useful rule of thumb for learners, is that quotations should always be acknowledged and always commented upon. Advice that a direct quotation of three-quarters of a page should receive a comment which is at least the same length does make students think twice about packing secondary information into thin essays. 


\section{HOME-BASED ASSIGNMENTS}

The final "prong" of the course is the home-based assignment, which acts as a culmination of the class-based activities, and is meant to encourage transfer of summarising and synthesising skills into full-blown assignments. The students are given an essay topic and two or three extracts from related articles as background reading. Such extracts may be up to two pages each in length. Students may add to this reading if they wish (library skills are taught elsewhere in the course), but they are required to make use of the given extracts, for obvious reasons: the teacher can maintain a measure of control over the material summarised and quoted, and therefore gauge the students' developing ability to appropriate the arguments of others. If this method sounds teacher-dominated, I would stress that the teacher is not seeking to influence the students' evaluation of the given material, but to monitor how this evaluation is achieved. With the general undergraduate group, choosing assignments with substantial academic content, and about which the learners may already have strong views, is the most successful teaching strategy. In a trawl of the university library, the teacher can usually come up with concise extracts giving differing views on favourite controversies, such as punishment (corporal and capital), the media (censorship of violence or sex), and women (stereotyping of, etc). Such extracts need not necessarily give incompatible information: some extracts demand the qualification of a strong claim to a weaker claim, or the synthesising of complementary positions to achieve a more rounded view of a subject. A regular diet of such activities should train students to handle background reading with a greater degree of awareness, confidence and sophistication.

I argued earlier that it is not generally advisable to end a piece of work with a quotation, but I shall anyway (quotation as pithy topiccloser). Bazerman (1988, p. 328) argues that good writing is good science. To paraphrase, developing student writing is the first step towards developing not just a greater control of language but a greater control of academic procedure. The learner develops strategies which help validate knowledge claims to the satisfaction of the academic community. It is this which makes the subject so fascinating and rewarding to teach. 


\section{NOTE}

This article is based on a paper of the same title, presented at the TESOL Convention in Vancouver, March 1992.

\section{THE AUTHOR}

Until recently, John Corbett was a Staff Tutor at the Centre for English Language Teaching, Stirling University, Scotland. $\mathrm{He}$ is now a Lecturer in Applied Linguistics at the Programme for Literary Linguistics, Strathclyde University, Scotland. His interests are academic reading and writing, functional grammar and genre analysis, and literature in ELT.

\section{REFERENCES}

Bazerman, C. (1988). Shaping written knowledge. Madison: University of Wisconsin Press.

Campbell, C. (1990). Writing with others' words. In B. Kroll (Ed.), Second language writing. Cambridge: Cambridge University Press.

Hoey, M. (1983). On the surface of discourse. London: George Allen and Unwin.

Jordan, M. (1984). The rhetoric of everyday English texts. London: George Allen and Unwin.

Swales, J. (1990). Genre analysis. Cambridge: Cambridge University Press.

Winter, E. (1982). Towards a contextual grammar of English. London: George Allen and Unwin. 